\title{
Reorganización territorial de la vida cotidiana y procesos de reparación moral tras el daño: un estudio de tres casos en el Oriente Antioqueño (Colombia) ${ }^{\mathrm{i}}$
}

Territorial Reorganization of Daily Life and Moral Reparation Processes After Damage: a Three-Case Study in the Eastern Region of Antioquia, Colombia.

\section{Por: Liliana Cecilia Molina Conzález ${ }^{1}$}

1. Profesora Asociada del Instituto de Filosofía-Universidad de Antioquia. Investigadora asociada al grupo "Cultura, violencia y territorio" (CVT), del Instituto de Estudios Regionales, de la Universidad de Antioquia. Investigadora principal del proyecto: Daño moral. Una exploración sobre el carácter simbólico y narrativo de la reparación moral. Medellín (Colombia). Orcid: https://orcid.org/0000-0002-1760-5909 Scholar: https://scholar.google.com/citations?user=b9AxH-cAAAA]\&hl=es

Contacto: liliana.molina@udea.edu.co

\section{G OPEN ACCESS}

\section{(c) (1) $\Theta(9$}

Copyright: (c) 2020 El Ágora USB.

La Revista El Ágora USB proporciona acceso abierto a todos sus contenidos bajo los términos de la licencia creative commons Atribución-NoComercial-SinDerivar 4.0 Internacional (CC BY-NC-ND 4.0)

Tipo de artículo: Investigación

Recibido: marzo de 2019

Revisado: abril de 2019

Aceptado: mayo de 2020

Doi: $10.21500 / 16578031.5132$

Citar así: Molina González, L. (2020). Reorganización territorial de la vida cotidiana y procesos de reparación moral tras el daño: un estudio de tres casos en el Oriente Antioqueño (Colombia).

El Ágora USB, 20(2). 88-101

Doi: $10.21500 / 16578031.5132$

\section{Resumen}

Al investigar las dificultades inherentes a los procesos de reorganización territorial tras el impacto del daño asociado al conflicto armado, se identifican cuestiones importantes para entender cómo las personas intentan recuperar la vida cotidiana cuando no cuentan plenamente con ayuda del Estado. Me refiero a la restauración de los lazos morales necesarios para la organización colectiva y la defensa de los territorios. Este artículo analiza cómo inciden las emociones en la capacidad de las comunidades para organizarse colectivamente; y las dificultades de los mecanismos estatales de reparación en tres localidades del oriente antioqueño.

Palabras claves: Conflicto; desarrollo regional; transformaciones socio territoriales.

\section{Abstract}

By investigating the difficulties inherent to territorial reorganization processes following the impact of the damage associated with armed conflict, important issues to understand how people try to recover daily life when they do not fully receive State aid are identified. I am referring to the restoration of the moral ties necessary for collective organization and the defense of territories. This article discusses how emotions affect communities' ability to organize collectively; and the difficulties of State reparation mechanisms, in three locations, in the Eastern Region of Antioquia. Keywords: Conflict; Regional Development; and Socio-Territorial Transformations. 


\section{Introducción}

Considerar los procesos de reorganización territorial en las regiones que han sufrido el impacto del daño asociado al conflicto armado, exige desplazarse a los territorios (Molina, Vieira, Cano, Pilz, Stegemann, 2015) y considerar la experiencia de las víctimas (Tapias Saldaña, Fajardo Sánchez, Gómez Díaz, Suárez Bustamante \& Velásquez Vargas, 2016; Comisión Colombiana de Juristas, 2007). Esta perspectiva muestra la necesidad de explorar los procesos locales (Centro Nacional de Memoria Histórica [CNMH], 2018) y las limitaciones de un enfoque exclusivamente normativo sobre la reparación en Colombia (Uprimny, 2009; De Greiff, 2006). Pues los procesos de reorganización colectiva, necesarios para reclamar las vías de reparación ofrecidas por el Estado en Colombia y para defender la riqueza medioambiental de los territorios, son la clave para entender las dificultades y retos de los procesos de reparación en general, incluyendo la reparación moral, una noción inseparable de la de daño moral.

Entendido como una alteración grave de las condiciones necesarias para la existencia (López, 2018, p. 92); como una lesión de los sentimientos que definen nuestras relaciones con los otros (Henao, 1998, p. 84), y de la capacidad para llevar a cabo proyectos comunes (Bello, 2014 , p.11), el daño moral es inseparable de la pregunta por la reparación moral, definible, a su vez, como el proceso de restaurar relaciones con los otros, las instituciones y las normas (Urban Walker, 2006a; 2006 b). Vale resaltar que, en Colombia, el Consejo de Estado incluye dentro de la categoría de daño inmaterial, al daño moral, además del daño a la salud, los bienes constitucionalmente protegidos y a los derechos humanos (López, 2018, p.88).

En este proceso las emociones tienen un rol protagónico pues el eje de la reparación moral es el esfuerzo constante de las personas afectadas por reconfigurar, intersubjetivamente, el tejido emocional (esperanza, confianza, y solidaridad lo ejemplifican) necesario para defender una forma de vida asumiendo las secuelas del daño padecido. Los espacios de la vida cotidiana expresan posibilidades espaciales e históricas y dependen de características territoriales; así como de una articulación entre aspectos materiales y simbólicos concretos. Brison (2002, pp.37-66) y Zehr (2001, pp.86197) hacen énfasis en que la recuperación de este tejido afectivo es clave para el proceso de vivir con las secuelas del daño. El componente emocional es clave, además, en la metodología empleada en Gómez (2014, pp.21-39) y en Riaño (2013, pp.62-117).

La circulación de las emociones permite establecer vínculos que definen nuestros espacios de vida y de relación con otros; pues su carga cultural y simbólica inviste la estructura normativa de una sociedad (Ahmed, 2004, p.12, pp.144-167, p.196). Por ejemplo, Veena Das (2008, pp.217-250) y Miriam Jimeno (2010, pp.99-121) analizan cómo la expresión del dolor produce una narrativa que transforma la subjetividad y puede propiciar el establecimiento de vínculos emocionales. Das $(2008,167)$ alude a un "compromiso de vida con un conocimiento envenenado"; y Jimeno, a la formación de comunidades emocionales. En consecuencia, las emociones configuran el ejercicio de dos capacidades necesarias para las transformaciones socioterritoriales: juzgar moralmente y actuar políticamente; además, propician (la esperanza, por ejemplo) actitudes necesarias para la organización territorial como la solidaridad y la confianza, ambas necesarias para defender y recuperar las tradiciones culturales lesionadas por el daño. Así, las emociones son formas de orientación (Ahmed, 2004, pp.13-14; 2006, pp.1-24) que disponen a ciertos cursos de acción y de elección; son performativas (Ahmed, 2004, pp.12-16; p.194) y expresan formas de relación con historias que circulan socialmente (Ahmed, 2004, p.7; pp.10-12). Esto explica por qué nuestra perspectiva moral depende de actitudes emocionales (Lindemann, 2001, 11).

A continuación, este artículo identifica algunas de las dificultades que se presentan, a nivel territorial, en los procesos de organización colectiva de las comunidades frente a los procesos de reparación estatal; enfatizando, especialmente, en la afectación emocional que expresan quienes han sufrido el desplazamiento forzado y han regresado a sus territorios para tratar de reconstruir 
su vida tras el impacto del daño. Pues los casos particulares pueden dar contenido concreto a lo que se define como reparación moral (Urban, 2006, pp.23-28). Siguiendo el caso de tres veredas del oriente antioqueño, el propósito de este artículo es identificar las múltiples maneras en que el daño, asociado al conflicto social armado en Colombia, produce una afectación emocional que incide en los procesos de transformación territorial entre los que se cuenta el proceso de la reparación de lazos morales, aquí nombrado con el término de reparación moral.

Para tal fin, este texto se divide en dos partes:

En la primera parte se establecen algunas pautas para entender el modo en que la violencia, asociada al conflicto armado colombiano, afecta emocionalmente la vida cotidiana y la capacidad de las comunidades para organizarse colectivamente. Además, se exponen los rasgos principales de lo que Urban Walker describe como reparación moral, mostrando que el análisis de casos concretos es la clave para entender los procesos de organización colectiva, y la reparación de los lazos que los sustentan.

En la segunda parte se describen los parámetros metodológicos (encuadre y actividades) del trabajo de campo realizado. Las observaciones se remiten a talleres realizados en el marco de dos proyectos de investigación sobre procesos de reparación en el oriente antioqueño (pertenecientes al mismo grupo de investigación); uno de los cuales tiene como énfasis la pregunta por los procesos de organización territorial y por los aspectos materiales y simbólicos de la reparación moral, desarrollados en tres zonas veredales del oriente antioqueño fuertemente afectadas por la siembra de minas y el desplazamiento forzado: Palmirita (Cocorná), Boquerón (San Francisco) y el corregimiento La Soledad (Ríos verdes de los Montes-Sonsón). Debido a su riqueza hídrica y ubicación estratégica, estos lugares se convirtieron en zona de disputa territorial por parte de diferentes grupos armados $y$, en consecuencia, en epicentro de diferentes formas de violencia que causaron el desplazamiento masivo de sus habitantes. Ambos aspectos las convierten, actualmente, en zonas apetecidas para el desarrollo de proyectos hidroeléctricos.

Finalmente se propondrán algunas conclusiones parciales circunscritas a las particularidades de las regiones mencionadas y al encuadre metodológico del trabajo de campo realizado. Al final se identifican dificultades y retos asociados a los procesos de reparación moral (de los cuales depende la transformación social de estos territorios), con el fin de mostrar que este proceso involucra no solo a sus vecinos sino a quienes como ciudadanos podemos apoyar y aprender de los procesos de reorganización territorial y del restablecimiento de la vida en común tras el daño.

\section{Conflicto social y armado en Colombia: daño moral y la pregunta por los procesos de reorganización territorial}

El artículo 25 de la Ley1448 de 2011, insiste en que “la reparación comprende las medidas de restitución, indemnización, rehabilitación, satisfacción y garantías de no repetición (..)” en dimensiones que incluyen lo individual, colectivo, material, moral y simbólico, como también se indica en el artículo 69. Además, el artículo 196 enuncia las medidas de satisfacción (relacionadas, como se indica en el artículo 139, con la verdad y el restablecimiento de la dignidad de la víctima), como medidas de compensación moral, pero el texto de la Ley 1448 no tematiza la reparación moral como una manera singular de reparación ni la importancia de su componente emocional o afectivo; más bien el carácter moral de estas medidas se subsume a la dimensión simbólica de la reparación, relacionada, principalmente, con el acceso a la verdad y con preservar la memoria. La jurisprudencia colombiana conceptualiza el daño moral como afectación de bienes tutelados, por eso la importancia de las medidas retributivas y pecuniarias como formas de compensación (además de las medidas de satisfacción).

Ahora bien, la pregunta por la reparación moral no es una pregunta relevante para el derecho sino para la filosofía moral, pues esta define el daño en términos de mal moral, como una acción 
intencional que consiste en instrumentalizar a los otros, negando, con ello, su condición de personas y su dignidad o valor moral (Card, 2010; Bernstein, 2002; Lara, 2001).

El mal moral se produce cuando se cosifica a sus víctimas, cuando se les niega la capacidad de agencia moral, derechos y ciudadanía. Esta definición aglutina la acción del actor del mal (negar la condición de persona y ciudadanía a sus víctimas), y sus consecuencias para la víctima (ver afectadas su agencia moral, derechos y proyecto de vida); además, permite preguntarnos cómo logran quienes han experimentado el daño, en todas sus dimensiones, construir procesos de articulación colectiva y qué papel juegan las emociones en este proceso. Pues las emociones no solo sustentan la vida cotidiana a nivel individual y social, sino que inciden (dificultan o propician) en procesos de transformación territorial, disponiendo a la organización colectiva (o impidiéndolo, según el caso). Desde esta perspectiva, el proceso de reparar lazos morales, necesarios para las transformaciones sociales en zonas afectadas por el conflicto armado, no se reduce a procesos jurídicos, ni se agota en los términos de la reparación simbólica institucionalizada en la Ley 1448 de 2011.

Justamente, en el contexto colombiano la ruptura de relaciones morales es un aspecto central para entender el daño moral asociado a la violencia que produce el conflicto armado y esto lo expresa Bello (2014, p.22) al decir que "el daño no solo afecta las dimensiones subjetivas e individuales de la víctima, sino que tiene expresiones familiares y colectivas. Individuos, familias y comunidades son 'sujetos de daño y reparación' en tanto en cada una de estas dimensiones, por demás, en estrecha interacción, se producen alteraciones y lesiones que causan transformaciones en la vida de las personas". Ser, hacer y estar en el mundo, delimitan tres esferas de la vida en que incide el daño moral, pues su impacto y secuelas expresan el menoscabo de la posibilidad de habitar el mundo (viabilidad de la propia existencia y forma de vida), de participar en él (acceso a derechos), y de actuar en él (organizarse con otros). El menoscabo de estas esferas significa perder autonomía y no gozar de agencia moral ni política. Pero también puede significar ser excluido de la comunidad moral, por ser percibido como incapaz de actuar responsablemente.

Lindemann (2001, pp.1-21) señala que las identidades son dañadas narrativamente cuando se consolidan historias o relatos que descalifican a individuos o grupos sociales, es decir, al cristalizar narrativamente la idea de que algunos individuos o grupos no son capaces de actuar responsablemente. Partiendo de esta idea, afirma que la reparación de estas identidades es de carácter narrativo y consiste en un proceso mediante el cual se configuran contrahistorias cuyo objetivo es reparar identidades dañadas.

Así planteado se entiende por qué el daño moral consiste en un menoscabo en las propias condiciones de existencia, entre las cuales habría que incluir, como lo hace el derecho, el perjuicio al honor y buen nombre; pero también, el perjuicio a la capacidad para elegir y llevar a cabo un proyecto de vida, como se enfatiza desde la perspectiva de la filosofía moral. Pues sin condiciones que permitan el ejercicio de la autonomía y de la agencia moral responsable, es difícil incentivar lazos morales, los cuales se sustentan en la confianza en normas morales compartidas. En suma, el daño moral consiste en una lesión de las condiciones necesarias para una vida digna, porque menoscaba la identidad (la percepción de uno mismo como sujeto moral y miembro valioso de una comunidad) y la confianza en el mundo, es decir, en las relaciones con los otros, en las normas y en las instituciones.

Desde la perspectiva del daño moral, entendido como ruptura de relaciones morales, el caso colombiano presenta un panorama complejo que exige más que las tipificaciones que ofrece el derecho sobre el daño en términos patrimonial y extrapatrimonial. Y se ve la necesidad de recurrir a los relatos de quienes han sido directa o indirectamente afectados por la violencia para sustentar una reflexión sobre el daño moral entendido como una ruptura de relaciones morales. Bello (2014, p.11) señala que normalmente el daño se reconoce por afectaciones visibles y concretas como las económicas o materiales, y esto explica la importancia dada a los perjuicios en relación con los impactos 
directos del daño. Sin embargo, una mirada circunscrita a los efectos visibles del daño soslaya otros factores que pueden ser claves para comprender el impacto de los hechos violentos en la vida de las víctimas y de sus comunidades. Como ella señala, un "análisis más integral" debe interrogar por las maneras en que se "afectó el proyecto de vida de personas, comunidades y organizaciones". Desde esta perspectiva, la comprensión de la reparación moral exige la revisión de casos concretos gracias a los cuales se puede obtener una mirada diferencial de los daños, considerando particularidades territoriales, sociales, culturales, políticas y económicas.

En el escenario de los daños asociados a la violencia generada por el conflicto armado, nos topamos con: (1) daños a individuos (daños individuales), es decir, daños emocionales, psicológicos, morales, que afectan su identidad (así como la de su familia y personas cercanas) y la capacidad para cumplir con proyectos de vida; (2) daños a las comunidades (daños colectivos), es decir, a los rasgos sociales, culturales, que definen su identidad como grupo y la capacidad de sus miembros para asociarse, para desarrollar proyectos comunes; (3) daños a la cultura, que inciden sobre la pérdida de su cosmovisión, de sus rituales, etc.; y (4) daños al medio ambiente, que son otra forma de los daños colectivos. En todos esos casos se crean rupturas, se erosiona la posibilidad de la relación sustentada en la confianza, la esperanza en proyectos comunes y, en consecuencia, se puede erosionar la capacidad para la solidaridad y el sentido de pertenencia, incluso de pertenencia a la tierra.

El daño al proyecto de vida implica un menoscabo de oportunidades para el desarrollo personal que no depende de quién es afectado. Este daño, se da en situaciones donde se violan las normas, produciendo una desconfianza en las instituciones y órganos de poder público que debían proteger los derechos de quien ha sido afectado de esta manera (Bello, 2014, p.18).

Como se señala en el informe ¡Basta Ya! Colombia: memorias de guerra y dignidad (Bello, 2013a), la violencia exacerbada del conflicto armado se manifiesta en masacres, torturas, desaparición forzada, ejecuciones extrajudiciales, desplazamientos, violencia sexual. En este último caso, el cuerpo de las mujeres se vuelve campo de guerra justamente porque ellas son las principales tejedoras de los lazos sociales en sus comunidades, son las depositarias y sostén principal, en muchos casos, del hogary de la memoria.

En el informe La verdad de las mujeres. Víctimas del conflicto armado en Colombia (Gallego, 2013, pp.99-100) se muestra, además, que retejer la vida depende de oportunidades para continuarla: educación, salud, atención psicosocial; entre otras, como el acceso a la verdad, y justicia. La reparación está asociada a prevención, desarme, superación del conflicto armado hacia un proceso de paz y solución política que ponga ante un nuevo ciclo la vida de la gente.

Adicionalmente, Bello (2013a, p.268) señala que el daño moral es:

Resultado del menoscabo de valores significativos para las personas y las comunidades, pues muchos de los actos violentos buscan, en efecto, degradar la dignidad de las personas y sus comunidades, devaluar ideales y creencias y violentar los valores más íntimos que sustentan la identidad colectiva.

En general, el daño se describe como el acto de violentar el sentido de comunidad y de pertenencia; como una ruptura de lo singular pero también de lo común o intersubjetivamente construido. De estos dos tejidos depende la percepción que una persona y una comunidad tienen de su identidad, de su tierra, de las posibilidades de una vida en común. En suma, el centro común del daño al "patrimonio" moral en el caso individual y colectivo es el deterioro en la capacidad para imaginar que sea posible continuar con la vida y con una vida en común. De allí que los daños asociados a la violencia del conflicto armado se definan como: "crímenes que, además, no son aislados, ni fortuitos y que son practicados con la intención explícita de destruir o desterrar vidas, ideales y valores humanos que se oponen a determinados propósitos de control y dominación: crímenes que causan terror y sufrimientos intensos de manera deliberada" (Bello, 2014, p.10). Este tipo de daños muestran que 
a las víctimas "se les ha impedido vivir como quieren, vivir bien y vivir sin humillaciones, tres condiciones que, a juicio de la Corte Constitucional, concretan la vida digna" (Corte Constitucional de la República de Colombia, Sentencia de Tutela 881).

Ahora bien, desde esta perspectiva compleja del daño ¿cómo entender la reparación moral? Urban (2006, p.8) afirma que en el marco de las discusiones filosóficas sobre el daño ha prevalecido la pregunta por las respuestas punitivas de la sociedad ante el daño cometido por quienes han infringido las normas morales y sociales que posibilitan una vida en común. En su opinión, se ha soslayado la pregunta por la reparación moral y por eso contamos con muchos debates sobre el papel de respuestas morales como el resentimiento, el deseo de venganza o el perdón, pero con pocas discusiones sobre las tareas de la reparación, ese proceso consistente en responder ante las secuelas del daño (por ejemplo, de la exclusión social, del desplazamiento, de la privación de condiciones de vida digna).

El antecedente de la pregunta por la reparación moral son las discusiones sobre justicia restaurativa en cuyo marco se plantea la implementación de medidas reparadoras. En este modelo de justicia se crea el contexto para hablar de reparación de lazos morales y sociales (Urban 2006a, pp.382-387; Zehr, 2014), entendidos como formas comunes de relación sustentadas en hábitos, concepciones, imaginarios y modos de actuar que definen una forma de vida común. La reparación moral alude a un proceso que exige, a quienes han sido afectados, encontrar modos de absorber o trascender el daño padecido; y de organizarse para hacer efectivas sus demandas de vida digna y retomar su vida cotidiana. El primer paso es, desde el punto de vista simbólico, darle un lugar a la voz de las personas afectadas, validarlas (Urban 2006, p.19); y esto se hace partiendo de que no hay reglas generales, sino que hay que construirlas con ellas cuando se trata de la reparación moral. Según la autora, el proceso de la reparación moral consiste en moverse de una situación de pérdiday daño a una situación donde se obtiene algún grado de estabilidad en las relaciones morales (Urban, 2006, p.23; p.28; p.38).

A propósito de esta hipótesis, se puede afirmar, con base en el trabajo de campo realizado, que el proceso de reparación moral depende, también, de procesos de organización colectiva. En estos procesos importa considerar la satisfacción de necesidades materiales concretas que son necesarias para la rearticulación de una vida en común (la escuela, la placa deportiva, el puesto de salud, la carretera, la placa-huella); y de los lazos familiares y comunes que existían en los territorios antes de los acontecimientos violentos.

Urban (2006, p.6) insiste en que la comunidad asume un costo consistente en absorber las pérdidas, los dolores o la ira por los daños padecidos. Durante el trabajo de campo esto puede observarse en la lucha comunitaria por articular acciones colectivas reparadoras de los lazos emocionales, es decir, los lazos sociales y morales necesarios para recuperar las potencialidades inherentes a la vida en común: este intento lo expresan los habitantes de las veredas al proporcionar formas de encuentros como los convites, que son actividades gestionadas por las comunidades para recoger fondos destinados a organizar la carretera o para mejorar sus fincas.

Según Urban, reparando dichos lazos se crea un escenario que posibilita la reparación de personas afectadas y de comunidades pues ella enfatiza en que el fin principal de la reparación moral, es reparar relaciones, una idea afín al marco de la justicia restaurativa (2006, 14-23). Pero esto depende, como he señalado, de un balance emocional que sustenta, en nuestro contexto, la confianza en instituciones del Estado como la defensoría del pueblo o la personería; las relaciones con los vecinos y, más aún, la reconciliación con la propia historia.

Para ilustrarlo, paso a situar el trabajo de campo realizado con un enfoque de investigación de acción participativa (IAP), el cual permitió explorar cómo los daños vulneran el tejido que conforman las emociones, base de la vida en común en los territorios, y cómo la erosión de este tejido puede dificultar los procesos de organización territorial y transformación social asociados con la reparación moral. Entendemos la reparación moral, de manera contextualizada, como el proceso mediante el 
cual se intenta retomar la vida, en los espacios de la cotidianidad, en medio de un esfuerzo común por sostener la esperanza y la confianza, así como la unión, pese a las secuelas del daño; se trata, por tanto, de un intento constante por defender y articular, cotidianamente, una forma de vida compartida después del daño.

\section{Metodología}

El trabajo de campo al que remite esta investigación se basa, principalmente, en la realización de una serie de tres talleres en cada vereda visitada (Palmirita, Boquerón y el corregimiento La Soledad), a los que asistieron de manera diferencial (según cada caso) entre 30 y 50 personas. La asistencia más masiva se tuvo en el corregimiento La Soledad (Ríos verdes de los Montes), donde en dos talleres se contó con la asistencia de más de 70 personas, algunas de las cuales venían de otras veredas cercanas (La capilla, Ciénaga, Santa Marta, Cabuyal). El propósito de estos talleres fue identificar la historia de los territorios visitados antes y después del desplazamiento; los daños padecidos, las emociones asociadas; e identificar lo que los vecinos han hecho para organizarse como comunidad, ante quién han recurrido y si han emprendido procesos de demanda de reparación ante el Estado colombiano.

El propósito de estos talleres, realizados entre 2018 y 2019, fue doble: explorar los daños, los actores responsables, las ayudas recibidas ante lo sucedido -identificando su fuente y periodicidad-; y explorar con los lugareños los caminos que han emprendido para la recomponer un sentido de comunidad, qué significa para ellos las vidas en sus comunidades, cómo articulan un relato al respecto y cómo este relato propicia la defensa de los recursos naturales de sus territorios, ricos en cuencas hídricas.

La línea del tiempo permitió identificar los momentos significativos para sus habitantes, respecto de la historia de la vereda, y el impacto y disrupción producido por los daños que tuvieron que enfrentar cuando sus territorios se convirtieron en zonas de disputa territorial por parte de grupos armados como ELN (Ejército de Liberación Nacional), FARC (Fuerzas Armadas Revolucionarias de Colombia), ejército y paramilitares. Además, se intentó identificar si en alguna de las veredas ha habido procesos de reparación (vía administrativa), y quiénes la han recibido.

Un aspecto importante durante estas actividades fue crear el espacio para que los asistentes pudieran expresar sus emociones asociadas al proceso de desplazamiento y al regreso a sus territorios, así como sus expectativas frente al futuro.

Dos cuestiones orientan las observaciones siguientes:

1. La inseparabilidad entre daños materiales (pérdidas materiales) y morales (menoscabo de emociones necesarias para recuperar y defender una forma de vida en común); y

2. Las dificultades en los procesos de reorganización social y territorial indispensables para la defensa de una forma de vida y de los recursos naturales de sus espacios territoriales.

\section{Resultados}

Respecto de (1) por qué el daño moral es inseparable del daño material, los habitantes de las veredas expresan que la pérdida de cultivos, animales y de las fincas, erosionó la relación con el territorio y con sus condiciones de vida antes del desplazamiento, pues muchas fincas tras ser abandonadas no pudieron ser recuperadas o tuvieron que ser vendidas debido, en el caso de algunos habitantes de Palmirita, a la extorsión; o, en otros casos, por endeudamiento. Algunos vecinos expresaron que para poder regresar tuvieron que endeudarse y aún siguen endeudados. Quienes han participado de los talleres reconocen la diferencia entre "retornar" (así se nombra el proceso de volver a los territorios, con acompañamiento y respaldo de parte de programas de gobierno, como Familias en su tierra) y 
regresar: los habitantes de Palmirita, Boquerón y La soledad hablan de "regresar" voluntariamente a sus territorios, para subrayar la ausencia de apoyo estatal.

Según los testimonios de los participantes en los talleres, el desplazamiento forzado se produjo entre 2003 y 2004 en Palmirita y Boquerón; y entre 2000 y hasta 2007 en La Soledad. El regreso a los territorios se da en Palmirita entre 2005 y 2007; en Boquerón, entre 2008 y 2012 y en La Soledad, desde el 2007. El desplazamiento forzado produjo pérdidas materiales y con ello el menoscabo de una forma de vida: la del campesino, que a través de su cuidado y aprovechamiento de la tierra no solo autogestiona su supervivencia, sino que afirma una manera de ser-estar y hacer en el mundo, la cual fortalece participando en espacios colectivos que definen su cotidianidad. Ejemplo de estos espacios son la junta de acción comunal (JAC); los festivales, convites y bailes (en el caso de Palmirita y de Boquerón; y menos en el caso de La Soledad) y las ferias campesinas. Además, todos coincidieron en que los daños padecidos, antes del desplazamiento, menoscabaron la vida en común en ese periodo de tiempo previo al desplazamiento (es decir, antes del 2003, año en que los habitantes de las tres veredas sitúan el comienzo del desplazamiento).

Entre los daños relatados se mencionan: siembra de minas, estigmatización (sobre todo en La soledad-Ríos verdes) o acusación de ser informantes de la guerrilla, por parte del ejército; y del ejército, por parte de la guerrilla; asesinatos, desapariciones, ejecuciones extrajudiciales (en Boquerón y en La soledad), retenciones forzosas, violaciones; entre otros. La mayoría de los daños se atribuye al frente 9 de las FARC, en las tres veredas; y al frente 47 (dirigido por la excomandante Karina), en el caso de La soledad-Ríos verdes.

Estos hechos previos al desplazamiento (masivo en el caso de Palmirita; gota a gota en el caso de La Soledad; y por familias, en el caso de Boquerón), lesionó la unión que caracterizaba su forma de vida, sobre todo en el caso de Palmirita y Boquerón. Ellos se refieren al hábito de reunirse para conseguir recursos que les permitían atender sus necesidades comunes de alimentación, por ejemplo, repartiendo cultivos. Según ellos, "nadie aguantaba hambre" pues todos repartían el excedente de la siembra. Otra cosa se relata en La Soledad, donde las condiciones geográficas difíciles del territorio y la distancia entre los caseríos no facilitaba ni entonces ni ahora tal grado de unión previa a la confrontación de grupos armados. En su caso, la estigmatización fuertemente sufrida por sus habitantes, tras el enfrentamiento y disputa territorial entre grupos armados, aun hoy les impide confiar en los otros y nombrar, con claridad, por ejemplo, a los actores de los daños (cosa que no sucede en el caso de las otras dos veredas).

En las tres veredas la relación entre lo material y lo moral-relacional, queda plasmada en la frase: "lo perdimos todo". En el caso de Boquerón se habla de la pérdida de la unión que había antes para hacer convites; en parte porque muchas familias no regresaron y se quedaron en el casco urbano. En el caso de Palmirita, el desplazamiento y el regreso fue masivo y se expresa menos la pérdida de la unión y del trabajo colectivo para responder a sus necesidades, con todo y las precariedades que aún heredan del desplazamiento y de los daños padecidos en sus fincas y casas. Esto obedece, probablemente, a que sus habitantes, antes y después del desplazamiento, son parte de núcleos familiares comunes. Pese a que en La Soledad se lamenta menos la pérdida de unión tras la llegada de grupos armados, porque no han sido tradicionalmente muy unidos, hay un aspecto en que todos coinciden sin duda: la defensa del río, que tiene un valor simbólico y material para ellos, pues el río es la herencia que todos coinciden en defender y en dejar a sus hijos para no dejarlo al arbitrio de proyectos hidroeléctricos.

Además de la nostalgia por la unión perdida, con los matices señalados, los habitantes de las tres veredas expresan haber sido afectados por la humillación y la estigmatización. En Palmirita muchos indicaron que fueron humillados, mal tratados por habitantes del casco urbano a donde se desplazaron (Cocorná en la mayoría de los casos); mal atendidos cuando iban a reclamar su derecho a la salud y muchas veces oían decir "ahí vienen los desplazados". Adicionalmente, manifestaron que, a 
sus hijos, en el colegio, los menospreciaban por ser desplazados. La humillación recibida de parte de personas encargadas de garantizar el acceso a derechos como la salud, o el registro como víctima en el registro único de víctimas, indica la producción de una ciudadanía de segunda dentro de su propio territorio, es decir, en los municipios a que pertenecen sus veredas (Cocorná, San Francisco y Sonsón).

Al identificar las emociones expresadas por los participantes de los talleres, es difícil separar su componente material (los daños en sus múltiples formas) de su componente moral (quiebre de relaciones), porque son expresión de afectaciones complejas. Entre las más nombradas están: miedo, zozobra, desarraigo, desesperanza, rabia, desconfianza, tristeza, incertidumbre. Como decía una de las personas de Palmirita: "sentimiento de pérdida y rabia al tener que ir a la ciudad a reclamar algo". En el caso de Boquerón, se expresa además de temory desarraigo, la nostalgia de dejarlo todo, "tener que sentarse y no poder hacer nada", una frase que resume el contenido de una emoción como la impotencia. En el caso de La Soledad, a las emociones mencionadas se suma una expresión que expresa lo que se siente cuando "uno se tiene que ir": "a uno se le junta el cielo con la tierra", la cual evoca la enunciación de la pérdida del lugar. Es importante notar que la expresión de la pérdida material de cultivos y de animales, evoca también la pérdida de las relaciones simbólicas con la tierra (territorio) y con los otros: la pérdida de cultivos, de la casa, del río, es también la pérdida de la posibilidad de reunirse, de poder responder a las precariedades comunes con lo que cada familia pudiese aportar.

Recapitulando, en las tres veredas se manifiesta que con el desplazamiento forzado se desarticuló su capacidad para actuar como colectivo. En esta desarticulación inciden aspectos materiales, por ejemplo, las deudas adquiridas por algunos para poder regresar, como en el caso de Palmirita; o aspectos emocionales como la pérdida de la confianza, debido a las secuelas de daños sufridos como la estigmatización de parte de diferentes actores armados, en La Soledad. En el escenario de los daños asociados a la violencia generada por el conflicto armado, se expresa la afectación de un tejido emocional necesario para la recuperación de relaciones morales estables y para la organización colectiva, como se puede notar en las siguientes observaciones:

1. Daños individuales, es decir, daños que afectan la identidad. Por ejemplo, en La soledad sus habitantes fueron obligados a convertirse en informantes de diferentes grupos armados y se produjo una desconfianza que aún es notable entre los habitantes de la vereda.

2. Daños a las comunidades (daños colectivos, entre los que se cuentan los daños morales y son inseparables de los daños individuales), que afectan la capacidad de sus miembros para asociarse. Por ejemplo, la siembra de minas, las amenazas de muerte, las extorsiones, el asesinato de líderes sociales y la violación de mujeres, lesiona la esperanza y la confianza en normas morales compartidas.

3. Daños a la cultura, que inciden sobre la pérdida de su cosmovisión y en este caso alude al menoscabo de costumbres como la de reunirse para hacer convites, mingas y festivales, que son para intentar recolectar fondos y sortear necesidades comunes, pero también espacios para celebrar la vida.

4. Daños al medio ambiente, que son otra forma de los daños colectivos. En el caso de Boquerón y La Soledad, además de la siembra de minas que aún asocian a ciertos lugares que evitan transitar, persiste el miedo ante la amenaza de que el río sea explotado por algún proyecto hidroeléctrico y la desconfianza (sobre todo en La Soledad) ante la llegada de personas extrañas a sus veredas debido a este temor.

En segundo lugar, respecto de (2) las dificultades en los procesos de reorganización en las veredas visitadas, los habitantes de La Soledad expresan que se ha minado, en general, la disposición a participar en proyectos comunes. Esto se da un poco menos en el caso de Palmirita y Boquerón, donde estos procesos se ven menos debilitados quizá por el trabajo de acompañamiento de la Asociación Campesina de Antioquia (ACA) y de organizaciones como el Movimiento social por la vida y la defensa del territorio (MOVETE). 
En el caso de La Soledad, prima la desunión y la desconfianza. Estas se manifiestan, por ejemplo, a la hora de nombrar, entre ellos mismos, quiénes han sido los actores del daño: la mayoría ofrece relatos fragmentados o dicen no saber con claridad quién fue el actor. Esto puede obedecer a varias razones: puede ser secuela de la estigmatización, pero también puede ser consecuencia de las condiciones geográficas del lugar, donde sus habitantes viven en sitios distantes entre sí que no disponen al fortalecimiento de sus relaciones. Es notable que el relato de los hechos acaecidos en este lugar se convierte en el relato de "lo que se puede decir", de allí su carácter fragmentario y a veces contradictorio, respecto de los actores del daño.

Por otro lado, respecto de cómo entienden la reparación promovida por el Estado, en las tres veredas hay una percepción de la reparación como "ayudas humanitarias" e indemnización o compensación monetaria; nada se indica, por ejemplo, sobre la reparación simbólica. En el caso de Palmirita y La Soledad prima la demanda de reparación individual, para reparar casas y fincas, de allí que se perciba la reparación en términos de ayudas. Esto visiblemente responde a las condiciones de precariedad de sus territorios, las cuales son anteriores a las afectaciones producidas en el marco del conflicto armado y consecuencia de la falta de políticas públicas que incidan positivamente en el desarrollo de estas veredas: en Palmirita, carecen de una escuela apropiada y de un modelo de educación rural; en Boquerón, no solo no tienen una escuela apropiada, sino que carecen de unidad de atención para la salud; y en La Soledad, carecen de carretera (al menos hasta mediados del 2019). La demanda de reparaciones individuales muestra la falta de un tejido colectivo idealmente fuerte, así como la ausencia de una comprensión de la reparación colectiva como un derecho que puede ser reclamado. Estos aspectos son síntomas de la necesidad de un proceso de fortalecimiento de lazos emocionales comunes como el que expresarían la esperanza y la confianza en las instituciones, así como de la necesidad de una formación política necesaria para la gestión de sus territorios.

No obstante, los aspectos descritos no expresan la totalidad de la vida en los territorios, pues pese a las dificultades mencionadas, en estos lugares la vida se abre camino a través de un intento común: el intento de sus habitantes por recuperar, en medio de las precariedades de sus territorios, la cotidianidad como expresión de una forma de vida común. Quizá en la vida cotidiana, en los espacios que la articulan en cada lugar, esté la clave para entender, en este contexto concreto, los procesos que involucra la "reparación" moral. Es importante señalar que cuando se habla de reparación moral no se niega el ámbito de las necesidades individuales ni materiales, pero sí se enfatiza en la necesidad de recuperar tejidos comunes que inciden sobre la capacidad de agencia moral y política de una comunidad. Y el material de ese tejido que permea la defensa de lo común estaría conformado por emociones morales que el daño erosiona, como la confianza, la esperanza o la solidaridad, las cuales se tejen, cada día, en los espacios donde se configura la vida como compartida con otros: la escuela, los espacios de reunión como las juntas de acción comunal (JAC), los convites, los torneos deportivos, los festivales musicales, las ferias campesinas. Justamente esos lazos se activan en los espacios en que se reúnen para discutir cómo oponerse a la entrada de hidroeléctricas en sus territorios.

De manera particular, en el corregimiento La Soledad se expresa reiteradamente, por ejemplo, que no esperan nada del Estado, excepto que "los mire de otra manera y los dejen permanecer en sus territorios". La gran mayoría señala la necesidad de defender el territorio de la implementación de proyectos que quieren arrebatarles lo poco que tienen, como el recurso hídrico. En el caso de Palmirita, a propósito de quiénes han sido reparados (indemnizados), se señala que el hecho de que solo dos personas hayan recibido indemnización "los desunió", porque han recibido muy poco por lo que perdieron y que están a la espera de las ayudas del gobierno. Sin embargo, al mismo tiempo, expresan que se reúnen regularmente para recoger recursos que permitan sostener la escuela y construir la placa-huella. Por estos motivos comunes organizan convites, festivales musicales, fiestas de retorno y actividades para desyerbar y mejorar las fincas. Respecto de la reparación, uno de los asistentes en Palmirita afirmó que "la reparación es un decir". El grupo concuerda en afirmar que "no se 
sentían recogidos en esa palabra 'reparación'"; que añoran "vivir tranquilos y recibir capital semilla" para poder usar lo que aprendieron en capacitaciones que algunos recibieron como desplazados en el casco urbano de Cocorná, cuando era un requisito asistir a esas capacitaciones para poder recibir bonos alimentarios.

Estas capacitaciones son medidas asistenciales, con las cuales el Estado buscaría implementar vías que garantizasen el mínimo de condiciones necesarias para una vida digna (superar los umbrales de vulnerabilidad). El problema es que no hay un apoyo económico (capital semilla) que les permita, a quienes participaron de esas capacitaciones, hacer uso de los oficios aprendidos. Además, al participar de estas capacitaciones quedaban registrados en bases de datos que luego usaron la Unidad para la Atención y Reparación Integral a las Víctimas (UARIV) para corroborar que se han superado los umbrales de vulnerabilidad y así justificar el retiro de las ayudas humanitarias. En general, en las veredas visitadas, la reparación tiene el sentido principal de ayuda e incluye para los asistentes a los talleres realizados, la expectativa de recibir servicios y bienes que pueden incluirse dentro de las políticas públicas de parte del Estado: como la construcción de una escuela, de un puesto de salud, la construcción de una carretera, entre otros. Es decir, sus demandas son de ayudas y de compensaciones o indemnizaciones económicas, y aluden a los deberes no cumplidos por el Estado, pues exigen reparación en términos de infraestructuras, programas de salud, escuelas, y acueducto.

Otro aspecto que es manifiesto, de manera incisiva por los habitantes de la vereda Boquerón, es su disposición a defender la posibilidad de vivir como campesinos, afirmando con esto la defensa de una forma de vida que los daños padecidos no les ha arrebatado totalmente. Para los participantes de los talleres en esta vereda el gobierno busca que el campesino se convierta en jornalero. Es importante anotar que en esta vereda ha habido dos concejales y esta circunstancia particular muestra una disposición a la organización colectiva y al emprendimiento de proyectos comunes; los cuales, desafortunadamente, pueden ser menoscabados por hechos como los montajes judiciales, como en el caso del líder social Ancizar Morales (Asociación Campesina de Antioquia [ACA], 2019). Importa notar que en su defensa de la dignidad del campesino (que no es obrero), se conjugan aspectos materiales y simbólicos: no se trata solo de la defensa de control territorial, sino de una forma de vida encarnada en una relación con la tierra y el territorio. En ese sentido, los participantes de Boquerón manifiestan que el campesino "no es obrero de multinacionales sino el que labra la tierra y saca los productos de la tierra”. En esta demanda suya se expresa cuánto viven con la amenaza de perder la tierra, otra vez, y, con ello, el control y defensa de los recursos naturales.

La dignidad del campesino la definen como "vivir en lo de uno, no ser explotado por nadie". En este caso la defensa de la tierra es una forma de defender la autonomía que les da su relación con su territorio, así como la posibilidad de responder a las necesidades comunes. En este sentido, los procesos que tienen lugar en los territorios, con sus especificidades concretas, ejemplifican las tareas que involucra un proceso como el de la reparación moral. Cuando se les preguntaba a los asistentes de Boquerón por las emociones asociadas al desplazamiento, en su caso se hizo hincapié en el desarraigo, no tanto en el miedo, ni en la desconfianza, como en el caso de Palmirita y La Soledad, respectivamente. Pues el desarraigo evocaba, para ellos, la pérdida del territorio del que depende, entre otras variables, la posibilidad de rehabilitar la vida cotidiana, de vivir juntos tras la experiencia del daño y con sus secuelas.

\section{Conclusiones}

Con base en el trabajo realizado, en general puede concluirse que se identifica el papel preponderante de las emociones en los procesos de organización territorial, y en el de la reparación de lazos comunes (morales) de los que depende la defensa del territorio, pues el territorio es la base de una forma de vida que busca recuperarse. A continuación, se enuncian algunas observaciones que respaldan esta 
conclusión general (y se circunscriben a las especificidades de los territorios visitados, así como al encuadre de los talleres realizados):

El daño moral asociado a la violencia que produce el conflicto armado, entendido como la desestructuración de relaciones que permiten la organización colectiva de las comunidades, se amplifica con las políticas de asistencialismo y de ayudas humanitarias. Los subsidios y capacitaciones de carácter obligado (relacionado con la posibilidad de recibir la ayuda de bonos alimentarios), no contribuyen al empoderamiento de las comunidades, porque son ayudas parciales (solo durante tres meses o hasta seis, en la mayoría de los casos) que no incentivan la autonomía de las personas desplazadas.

Los habitantes de Palmirita expresaron que las capacitaciones recibidas no son respaldadas con recursos materiales, es decir, con capital semilla (como lo nombran los habitantes de las veredas), que permita a las personas entrenadas en talabartería, peluquería, confecciones etc., usar los saberes adquiridos para su autosostenimiento. Estas capacitaciones obligatorias para recibir bonos alimentarios y las ayudas humanitarias no redundan en su autonomía, sino que generan dependencia, endeudamiento y falta de esperanza; así como impotencia y desconfianza, según lo expresaron abiertamente algunas personas en los talleres realizados en Palmirita. Todos estos factores inciden, además, en la consolidación de una cultura del individualismo, la cual se puede observar en las demandas de reparación individual. Esto indica la necesidad de pensar que la preocupación por lo colectivo es una disposición moral y política por construir, más en el caso de un proceso como el de la reparación de las relaciones menoscabadas por el daño.

El daño ocasionado por el conflicto armado ha menoscabado la capacidad para actuar colectivamente, como se ve, en diferentes grados, en las veredas visitadas, y esto se expresa con emociones como el miedo, la desconfianza y el temor constante a ser engañados. La expresión de este tipo de emociones puede interpretarse no solo como una dificultad en el proceso de reparación moral dentro de las comunidades, sino como un reto para los procesos de acompañamiento en estas zonas territoriales tan afectadas por la violencia. Identificarlas es el primer paso en un largo proceso de reparación de lazos que no compete solamente a los habitantes de estas zonas veredales.

El concepto jurídico de reparación dista de la manera en que las comunidades visitadas entienden la reparación: pues desde su experiencia y condiciones precarias de vida, la reparación es nombrada principalmente como ayuda, no se entiende aún como un derecho. Esto muestra que las comunidades aun necesitan reconocer la reparación como un derecho; se trata aún de una categoría ajena a su experiencia cotidiana. Esta brecha ejemplifica cómo los lenguajes burocráticos impersonalizan la experiencia del daño (Das, 2008). Esta desarticulación entre el concepto jurídico de reparación y el mundo de sentidos de las comunidades debe analizarse a la hora de elaborarse una reflexión más detenida sobre las dificultades y límites de la reparación moral.

La reparación moral, agenciada por la comunidad, no es independiente de la respuesta, por parte del Estado, ante las necesidades materiales expresadas por las comunidades, cuya satisfacción es necesaria para poder defender la posibilidad de una vida común: me refiero a la satisfacción de necesidades que son derechos como el acceso a la salud (unidad sanitaria), el acceso a la educación (mejora de las escuelas y de la educación rural, la necesidad de preparar maestros formados en educación rural); y por ejemplo, la construcción de una carretera que facilite el desarrollo de comercio justo. Así, una de las conclusiones principales del trabajo de campo realizado hasta el momento es que los procesos de reparación moral difícilmente se desatan sin la satisfacción de necesidades materiales concretas y propias de contextos particulares. Y la reparación que ofrecen los mecanismos estatales, como indemnización, no se conecta con ese proceso mediante el cual las comunidades articulan lo que Das (2008) Ilama "un descenso a la vida cotidiana", configurada en los espacios que permiten imaginar una forma de vida. 
La tenencia de la tierra, la posibilidad de cultivary de un comercio justo, aparece como un factor que reviste un carácter material pero también simbólico, dada la importancia de la tierra y del territorio para defender una forma de vida como la del campesino que se resiste "a ser obrero o jornalero de una multinacional". Así la defensa de un territorio no alude solo a control social ni territorial, sino a la defensa de una forma de vida que expresa, a su vez, la defensa de una subjetividad y de una experiencia del mundo.

Si el daño moral se puede entender como la pérdida de las relaciones que dependen del territorio (los otros, la tierra, etc.), la reparación moral o recuperación y defensa de las posibilidades de una vida en común, depende, en estos territorios, del acceso y cultivo de la tierra, así como del cuidado y defensa de recursos como el rio. En muchas zonas del oriente antioqueño, ricas en recursos hídricos, la tierra y el río son los medios para subsistir, pero también son símbolo del hogar, de tener un lugar en el mundo, de poder aparecer en el mundo como sujeto ante otros. Ejemplo de ello es que ante la amenaza de que les sean arrebatados la tierra o el acceso a los recursos naturales como el rio, algunos habitantes del corregimiento La Soledad prefieren que no haya, por ejemplo, carretera. Pues las dificultades de acceso a su vereda han impedido la llegada de macro-proyectos que amenazan su forma de vida y los recursos naturales que la sustentan, aunque dificultan, al mismo tiempo, la posibilidad de un comercio justo.

En suma, en este artículo importa finalizar señalando que el daño que produce la violencia, sus secuelas e impactos, a nivel individual y colectivo, remite a tres niveles de relación que definen la vida cotidiana y las posibilidades de un proceso como el de la reparación moral: (1) la relación con el territorio, articulado en espacios que definen las posibilidades de encontrar un lugar para habitar y hacer inteligible el modo propio de vida; (2) la relación con otros, que se teje a través de vínculos emocionales que sostienen la acción intersubjetiva y vehiculan proyectos comunes. Entre esas emociones se pueden incluir dos básicas: la solidaridad y la esperanza, pues ambas disponen a recuperar los espacios entre y con los vecinos. Y, finalmente, (3) la relación con la propia trayectoria vital, es decir, con la propia historia en tanto vida sentida y vivida como una experiencia de mundo situada localmente. Pues para poder actuar con otros es indispensable ser reconocido como sujeto moral (responsable) y político (ciudadano), pero esto depende de que cada uno pueda sentirse como miembro de una comunidad concreta y ser reconocido por ella como una parte valiosa suya.

\section{Referencias bibliográficas}

Ahmed, S (2004). The Cultural Politics of Emotion. Edinburgh: Edinburgh University Press.

Ahmed, S. (2006). Queer Phenomenology. Orientations, Objects, Others. Durham: Duke University Press.

Asociación Campesina de Antioquia [ACA]. (12 de marzo de 2019). Detenido Ancísar Morales por Falsas Acusaciones. Obtenido de sitio web de la Asociación Campesina de Antioquia [ACA]: https:// www.acantioquia.org/es/component/k2/item/438-comunicado-publico.html

Bello, M. N. (2013a). ;Basta ya! Colombia: Memorias de guerra y dignidad. Informe general Crupo de Memoria Histórica. Bogotá: Centro Nacional de Memoria Histórica.

Bello, M. N; Mosquera, C.; Ortegón, J.; Quishpe, C.; Sepúlveda, E. (2013b). Debates en torno a las víctimas del conflicto armado interno dentro del actual proceso de negociación de finalización del conflicto. Documento de políticas públicas No 1. Bogotá: Centro de pensamiento y seguimiento al diálogo de paz - Universidad Nacional de Colombia..

Bello, M.N. (2014). Aportes teóricos y metodológicos para la valoración de los daños causados por la violencia. Bogotá: Centro Nacional de Memoria Histórica.

Bernstein, R. (2002). Radical Evil. A Philosophical Interrogation. USA: Blackwell.

Brison, S. (2002). Aftermath. Violence and the Remaking of a Self. Princeton: Princeton University Press.

Card, C. (2010). Confronting Evils. Terrorism, Torture, Cenocide. Cambridge: Cambridge University Press.

Centro Nacional de Memoria Histórica. (2018). Regiones y conflicto armado. Bogotá: CNMH.

Comisión Colombiana de Juristas. (2007). Verdad, justicia y reparación: algunas preguntas y respuestas. Bogotá. 
Das, V. (2008). "El acto de presenciar. Violencia, conocimiento envenenado y subjetividad"; "Trauma y testimonio". En: F. Ortega (Ed.), Veena Das: sujetos del dolor, agentes de dignidad, pp.145-167. Bogotá: Universidad Nacional de Colombia - Pontificia Universidad Javeriana.

De Greiff, P. (2006) (Ed.). The Handbook of Reparations. Oxford: Oxford University Press.

Díaz, C., Uprimny,R., Sánchez, N. (2009). Reparar en Colombia: dilemas en contextos de conflicto, pobreza y exclusión. Colombia. ICT].

Callego, M. (2013). La verdad de las mujeres. Víctimas del conflicto armado en Colombia. Versión resumida. Bogotá: Ruta Pacífica de las Mujeres.

Cómez, D. (2014). Aunque no estés conmigo: experiencias narrativas de víctimas del conflicto armado. Medellín: Museo Casa de la Memoria - Tragaluz editores.

Henao, J.C. (1998). El daño. Bogotá: Universidad Externado de Colombia.

Jimeno, M. (2010). "Emoções e política. A vítima e a construção de comunidades emocionais". Mana: Estudos de Antropología Social, 16(1): 99-121.

Lara, M. (2001). Rethinking Evil. Contemporary Perspectives. Berkeley: University of California Press.

Ley 1448. Por la cual se dictan medidas de atención, asistencia y reparación integral a las víctimas del conflicto armado interno y se dictan otras disposiciones. 10 de junio de 2011. D. O. No. 48.096.

Lindemann, H. (2001). Damaged Identities, Narrative Repair. Ithaca: Cornell University Press.

López, A. C. (2018). "La dicotomía de la reparación simbólica frente al daño inmaterial y las violaciones a los Derechos Humanos. La evolución de las categorías del daño y su reparación en la jurisprudencia del Consejo de Estado de Colombia". En: Y. Sierra León (Ed.), Reparación Simbólica: Jurisprudencia, Cantosy Tejidos. Bogotá: Universidad Externado de Colombia.

Molina, A.; Vieira, J.; Cano, D.; Pilz, M.; Stegemann, J. (2015). Víctimas y reparación: estrategias productivas en el marco del conflicto armado en cuatro municipios del Oriente de Caldas, Colombia. Manizales: Editorial Universidad Autónoma de Manizales.

Riaño, P. (2013). Recordar y narrar el conflicto. Herramientas para reconstruir memoria histórica. Colombia: Centro Nacional de Memoria Histórica - University of British Columbia.

Sierra León, Y. (2018) (Ed.). Reparación simbólica: Jurisprudencia, cantos y tejidos, Bogotá: Universidad Externado de Colombia.

Tapias Saldaña, A. C.; Fajardo Sánchez, L. A.; Cómez Díaz, L. P.; Suárez Bustamante, G.M.; Velásquez Vargas, M. A. (2016). ¿Reparación o revictimización? Cumplimiento de los fallos por parte de la Corte Interamericana de Derechos Humanos por parte del Estado colombiano. Bogotá: Universidad de Santo Tomás.

Urban Walker, M. (2006a). Moral Repair. Reconstructing Moral Relations after Wrongdoing. Cambridge: Cambridge University Press.

Urban Walker, M. (2006b). "Restorative Justice and Reparations". Journal of Social Philosophy 37 (3): 377-395.

Zehr, H. (2001). Transcending. Reflections of Crime Victims. Canada: Cood Books.

Zehr, H. (2014). The Little Book of Restorative Justice. New York: Good Books.

Nota

' Artículo producto de investigación titulada: Daño moral. Una exploración sobre el carácter simbólico y narrativo de la reparación moral. Este proyecto fue aprobado para su financiación (durante tres años) por el comité para el desarrollo de la investigación (Acta registro: 2016-12869) en la convocatoria programática área de Ciencias Sociales, Humanidades y Artes. Esta investigación comenzó en octubre de 2017 y termina a finales de enero de 2021. 